\title{
VARIETY SEEKING: CONCEPTUAL MODEL IN INFORMATION TECHNOLOGIES DOMAIN
}

\author{
Edgardo R. Bravo, Universidad del Pacifico, Lima-Peru,er.bravooo@up.edu.pe \\ Christian Fernando Libaque-Saenz, Universidad del Pacifico,Lima-Peru, cf.libaques@up.edu.pe
}

\begin{abstract}
Information technologies have changed social media consumption. For example, competition between online streaming companies (e.g., Netflix) and cable TV firms have risen although these two services do not offer the same content. Our research argues that in this case consumers may be motivated to alternate between services to increase utility, rather than completely replace one service by the other. Previous research has focused on technology adoption, technology usage continuity, and switching to a new technology. However, alternating between technologies remains unexplored. Grounded on motivation theory, our proposed research model synthesizes the contributions from fields like psychology and marketing to find potential antecedents to user alternating behavior of technologies: OSL, ASL, variety seeking, intrinsic and extrinsic motivations, and product characteristics. We will conduct a survey among USA users to gather data about these variables and validate their significant impact on alternating behavior of technologies. A pilot test will be conduct to refine our measurement items, whereas the full sample will be assessed in terms of reliability, validity, and explanation power. The results are expected to validate our model for explaining this relatively new behavior in the use of technologies, whereas they could suggest managers which strategies they can focus on to remain competitive in the market and co-exist with other technologies offering similar services.
\end{abstract}

Keywords: Alternating behavior, cable TV, Netflix, OSL, variety seeking.

\section{INTRODUCTION}

Information technologies (ITs) have revolutionized our lives. ITs have not only changed the way we communicate, but also our consumption of services. Social media is one of these services. Online streaming market has grown widely with the launch of new services such as Netflix. These new services have been threatening traditional cable TV firms. For example, $4.5 \%$ of cable TV subscribers stopped using this service in USA by 2010 , while this number increased to $6.5 \%$ by 2013 (Stenovec, 2014). However, these services do not offer the same content as cable TV. In the case of Netflix, this service offers third-party content and series that are not offered on cable TV, whereas cable TV service provides contents from broadcasters that are not on Netflix. In addition, low prices, capacity to manage time and space to enjoy the service and absence of advertisement are among the benefits of Netflix.

Accordingly, cable TV firms are worried that online streaming services take them out of the market. We argue that contrary to cases with a complete replacement of technologies (e.g., replacement of black-and-white TVs by color TVs), in the case of cable TV and Netflix, consumers may be motivated to alternate between both services to access a wide variety of content. Similar phenomena of coexistence of products have been studied in marketing literature (e.g., Helm and Landschulze, 2009; Orth and Bourrain, 2005; Steenkamp and Baumgartner, 1992). These studies explain that one of the reasons for an alternating behavior (variety seeking) is to increase utility (e.g., Givon, 1984). In fact, new products do not always replace completely similar ones, but they are used alternately to increase utility.

In the case of technologies, however, prior theoretical models focus on technology adoption for the first time (e.g., Davis, 1989), continuous use of technologies without considering the effect of alternative technologies (e.g., Bhattacherjee and Lin, 2015), or switching costs that implies a total replacement of technologies (e.g., Huang and Hsieh, 2012). These current models assume the existence of a unique technology capable to fulfill a need, and that similar technologies are independent of each other. These assumptions may not be true in media usage given that 
technologies may complement each other's content. Therefore, there is a lack of theoretical background for explaining user behavior of alternating between technologies. We argue that alternating models of marketing literature could serve as a theoretical basis to explain why technologies such as cable TV and Netflix are being alternated rather than replaced. Accordingly, the objective of our research is to develop a model that outlines which individual factors may explain the behavior of alternating in the context of technologies. It is expected that our results shed light on a conceptual framework to explain this phenomenon, and also provide social media companies with appropriate guidelines and strategies to remain competitive in the market and offer high value added to consumers.

\section{BACKGROUND}

\section{Variety Seeking}

Alternating behavior has been studied as the result of individuals' tendency for seeking variety among products and services they consume (e.g., Helm and Landschulze, 2009; Orth and Bourrain, 2005). Prior research has addressed variety seeking (VS) from two perspectives, as tendency and as behavior. As tendency, VS refers to the inclination of individuals to alternate among familiar alternatives (Helm and Landschulze, 2009). This tendency of switching products, according to the typology proposed by Raju (1980), is one of the exploratory user behavior tendencies, along with adopting new products and seeking information of curiosity. On the other hand, variety seeking as behavior (VSB) refers to the observable aspects of consumer behavior that are driven by the inclination toward variety and reflect the utility gained by the consumption of different items (Steenkamp and Van Trijp, 1991). According to marketing literature, the switch inherent to VSB is driven by the gained utility of the change itself, and the low utility derived from repetitive purchases (Bawa, 1990; Givon, 1984). VSB is defined as a "biased behavioral response (...) to a specific item relative to previous responses (...), due to the utility inherent in variation per se, independent of the instrumental or functional value of the alternatives or items" (Van Trijp, 1995). This behavior is product-specific, that is, it may happen in some categories of products (or services) and be absent in others (Van Trijp, Hoyer, and Inman, 1996). McAlister and Pessemier (1982) suggested that VSB could be studied by dividing individuals into two groups: 1) those who enjoy variation itself (intrinsically motivated), and 2) those who rely on varied behavior to obtain an external benefit (extrinsically motivated).

In the context of media, users may also present an alternating behavior because one service may not fully fill their need of content consumption. For example, Netflix's content could complement the content of cable TV and vice versa. Accordingly, users may be motivated to alternate between these two services to fill their needs rather than rely only on one of them. Our study attempts to test theory from marketing literature in the context of alternating between technologies.

\section{Intrinsic and Extrinsic Motivation}

As explained in the previous section, motivation is an important driver of VSB. Motivations have been used to explain individual engagement with various behaviors (Petri and Govern, 2006). Motivation is defined as an internal process that selects and directs behavior toward a goal (Zimbardo, Johnson, and McCann, 2012). Selfdetermination theory (SDT) divides motivation into two categories: intrinsic and extrinsic motivation (Deci and Ryan, 1985). This categorization is aligned with the VSB approach of dividing individuals engaged in alternating behavior into intrinsically and extrinsically motivated. Intrinsic motivation refers to "doing an activity for its inherent satisfactions" (Ryan and Deci, 2000), while extrinsic motivation happens "whenever an activity is done in order to attain some separable outcome" (Deci and Ryan, 1985). According to SDT, individuals are motivated to perform certain behavior to fill psychological needs (Deci and Ryan, 1985).

In the context of technologies, motivation theory has been widely used to analyze user adoption. For example, Davis, Bagozzi, and Warshaw (1992) used this theory to study technology adoption at work. Perceptions of the extent to which users enjoy the usage of technology (perceived enjoyment) were used to capture intrinsic motivation, while perceptions of the extent to which technology can improve job performance (perceived usefulness) were used as extrinsic motivation. Both types of motivations were found to have a significant impact on technology adoption (Davis et al., 1992). Likewise, Teo, Lim, and Lai (1999) and Yoo, Han, and Huang (2012) validated these results in the context of Internet and e-Learning adoption, respectively. Our study attempts to validate motivation theory in the context of alternating between technologies. 


\section{Optimal Stimulation Theory}

Optimal stimulation level (OSL) refers to the specific level of stimulation preferred by individuals (Berlyne, 1960). OSL represents an important psychological paradigm for VSB. Individuals who have high OSL tend to seek for variety more than those who have low OSL (Van Trijp et al., 1996). Prior literature on VSB has studied the relationship between OSL and alternating behavior (e.g., Raju 1980; Steenkamp and Baumgartner, 1992). Previous findings suggest that OSL is determined by personality, cultural factors, learning and individual psychological state (Berlyne, 1960), and is relatively constant in time (Helm and Landschulze, 2009).

An important extension of OSL is the concept of actual stimulation level (ASL). ASL is defined as the level of stimulation an individual perceives to exist in the environment at a particular time (Steenkamp, Baumgartner, and Van der Wulp, 1996). The importance of this concept lies on its discrepancy with OSL. According to Orth and Bourrain (2005), when ASL is lower than OSL individuals are motivated to increase stimulation and vice versa when ASL is higher than OSL. Hence, individuals are motivated to modify the stimulation from the environment (i.e., ASL) towards their OSL. Consumers will engage in VS if the stimulation inherent to this switch resolves the discrepancy between ASL and OSL (Van Trijp et al., 1996).

\section{Product Characteristics}

Van Trijp et al. (1996) postulates that VS is a phenomenon that depends on consumer perception of the characteristics of the product. Five characteristics that may be related to the VSB were proposed:

- Product involvement, defined as "the subjective perception of the personal relevance of an object, activity, or situation, has goal-directed arousal capacity" (Park and Mittal, 1985);

- Strength of preference, defined as the degree of preference in favor of one specific product;

- Purchase frequency, which refers to the repetitive decision process of acquiring the same product or brand;

- Hedonic features of the products, defined as the level of pleasure perceived by individuals when consuming a product;

- Differences among alternatives, defined as the perceptual differences in quality between products (Van Trijp et al., 1996).

In our study, strength of preference and difference among alternatives were chosen to be relevant in the context of cable TV versus Netflix.

\section{CONCEPTUAL MODEL}

Our research model is presented in Figure 1.

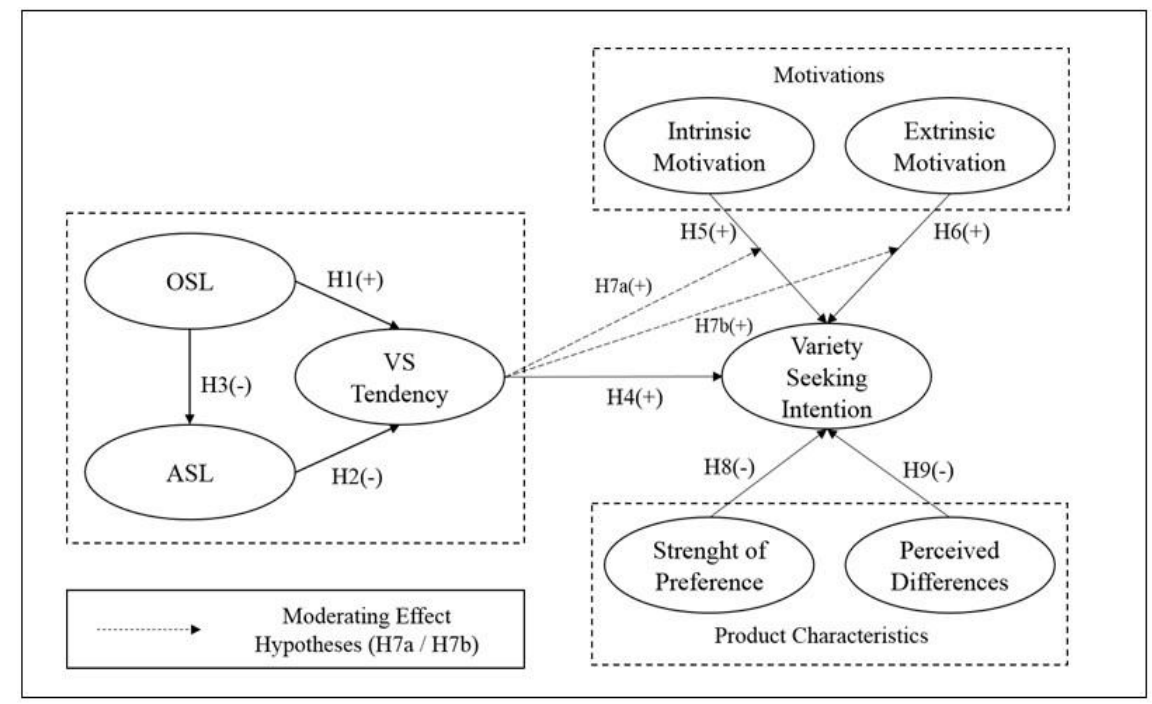

Figure 1. Research Model 


\section{Relationship between OSL, ASL, and Variety Seeking Tendency}

According to Helm and Landschulze (2009), OSL is an important factor determining consumer exploratory tendency. OSL represents individual preference of a certain level of stimulation (Berlyne, 1960), while VS tendency is a domain-personality concept that refers to stimulation regulation through varied product consumption (Steenkamp and Van Trijp, 1991). Raju (1980) postulated that consumers with high OSL tend to explore new stimuli based on their high need for environmental stimulation. In contrast, consumers with low OSL tend to withdraw from unusual situations (Raju, 1980). Considering that VS is an example of exploratory tendency, we propose the hypothesis:

H1: Individuals' OSL has a positive effect on variety seeking tendency.

Optimum stimulation theory postulates that searching for stimulation is not driven only by OSL, but also by actual stimulation level (i.e., ASL) (Wahlers and Etzel, 1985). ASL refers to individuals' perceptions of the level of stimulation of a specific environment (Wahlers and Etzel, 1985). Prior studies integrated both OSL and ASL in exploratory-tendency models and suggest that ASL (e.g., Helm, Gierl, and Stumpp, 1999; Orth and Bourrain, 2005). In addition, OSL theory postulates that ASL has a relationship with both OSL and variety seeking (stimuli). As for the first relationship, OSL may regulate ASL as follows: when the stimulation derived from the environment (i.e., ASL) is low (high), individuals tend to increase (diminish) stimulation towards the OSL to achieve psychological consistency (Orth and Bourrain, 2005). In the second relationship, if ASL increases, then individuals may be motivated to reduce the stimuli (variety seeking) to be consistent with their OSL. Likewise, if ASL decreases, individuals may be motivated to increase the stimuli (variety seeking) to achieve consistency with their OSL. In other words, it is expected a negative impact of OSL on ASL along with a negative impact of ASL on VS tendency (stimuli). We hypothesize:

H2: Individuals' ASL has a negative effect on variety seeking tendency.

H3: Individuals' OSL has a negative effect on individuals' ASL.

\section{Relationship between Variety Seeking Tendency and Intention}

As discussed in section 2.1, VS tendency is defined as the inclination of individuals to alternate among familiar alternatives (Helm and Landschulze, 2009), while VSB is defined as the observable aspects of consumer behavior that are driven by the inclination toward variety (Steenkamp and Van Trijp, 1991). Individuals "characterized by general exploratory behaviors should behave accordingly when it comes down to purchase [or consumption] decisions" (Helm and Landschulze, 2009). Therefore, consumers who are high on VS tendency are motivated to engage in VSB (Steenkamp et al., 1996). Our study focuses on intention as a proxy measurement of behavior, which is aligned with prior research (Ajzen, 1985). We defined intention as user willingness to alternate between Netflix and cable TV services (variety seeking intention). Accordingly, we hypothesize:

H4: Variety seeking tendency has a positive effect on intention.

\section{Relationship between Motivation and Intention}

As discussed in previous sections, SDT postulates that motivations influence individuals' decisions to perform a behavior (Ryan and Deci, 2000). Considering that our study uses intention as a proxy measurement of behavior, a relationship between motivations and intention is expected. In the case of intrinsic motivation, which refers to alternate between Netflix and cable TV services for the inherent satisfaction of doing it, we expect that as the satisfaction derived from alternating between technologies increases, user intention to engage in this behavior increase as well. This relationship has been widely studied and there is evidence linking internal motivational factors with VSB (e.g., Helm and Landschulze, 2009; Orth and Bourrain, 2005). Accordingly, we suggest the existence of a positive impact of intrinsic motivation on intention as follows:

H5: Intrinsic motivation has a positive effect on variety seeking intention.

As for extrinsic motivation, this variable in our study refers to the alternating between Netflix and cable TV services to attain some separable outcome, such as the access to a wide variety of content. The higher a user values the potential access to varied content, the more probable will be that the user would engage in this alternating 
behavior. This relationship has been validated by prior research in similar contexts of technologies (e.g., Davis et al., 1992; Teo et al., 1999). We hypothesized:

H6: Extrinsic motivation has a positive effect on variety seeking intention.

\section{The Moderating Effect of Variety Seeking Intention}

Prior literature postulates that personality characteristics have a moderating effect on the relationship between motivations and VS intention (Ha and Jang, 2013). Allocentricity and psychocentricy are opposed personality characteristics. The former characterizes individuals who are more likely to seek new experiences, while the latter characterizes those individuals who prefer familiar choices (Ha and Jang, 2013). In our study, individuals who are high on VS tendency are more allocentric than psychocentric because they are motivated to seek new experiences by alternating technologies. In contrast, those who are low on VS tendency are more pshycocentric than allocentric because they are motivated to use their most familiar technology. Accordingly, we argue that VS tendency has a moderating effect on the relationship between motivations and VS intention. Given a fixed motivation level, the higher the VS tendency of an individual the more sensitive will be his or her response to these stimuli because "people with personalities highly associated with exploratory behaviors are more likely to seek variety in their consumption situations" (Ha and Jang, 2013, p. 158).

H7a: Variety seeking tendency positively moderates the effect of intrinsic motivation and intention. H7b: Variety seeking tendency positively moderates the effect of extrinsic motivation and intention.

\section{Relationship between Product Characteristics and Intention}

Behaviors such as VS that regulate stimulation depend on product characteristics (Hoyer and Ridgway, 1984). Our study considers two variables: strength of preference and perceived differences between brands (Van Trijp et al., 1996). We define strength of preference as the degree of propensity in favor of Netflix or cable TV services. If users possess a strong preference for one of these two services, VSB may be less likely to occur. On the other hand, we define perceived differences between brands as individuals' beliefs that one technology-Netflix or cable TV - has better quality than the other. If users perceive that differences between technologies are high, the technology with the highest perceptual quality is likely to be chosen consistently over time (Bass, Pessemier, and Lehmann, 1972)_-VSB is less likely to occur. Accordingly, a negative impact of these product characteristics on intention is expected.

H8: Strength of preference has a negative effect on variety seeking intention.

H9: Perceived differences between technologies have a negative effect on variety seeking intention.

\section{METHOD}

\section{Measurement Instrument}

Variety seeking intention (VSI) will be measured with four reflective items from Bhatacherjee (2001) and Helm and Landschulze (2009), variety seeking tendency (VST) with four reflective items from Helm and Landschulze (2009), OSL and ASL with respectively four and three reflective items from Helm and Landschulze (2009), strength of preference (SP) and perceived differences (PD) with respectively one and three reflective items from Van Trijp et al. (1996). Items for intrinsic (MOTI) and extrinsic (MOTE) motivations will be adapted from selfdetermination theory in the information technology domain with three items each one (Davis et al., 1992). Table 1 shows all our items. 
Table 1. Measurement Items

\begin{tabular}{|c|c|c|}
\hline \multicolumn{2}{|r|}{ Items } & Scale \\
\hline VSI01 & $\begin{array}{l}\text { I intend to change between technologies (Netflix or Cable TV) to } \\
\text { have a little variety. }\end{array}$ & \multirow{4}{*}{$\begin{array}{l}1=\text { Strongly Disagree } / 7 \\
=\text { Strongly agree. }\end{array}$} \\
\hline VSI02 & $\begin{array}{l}\text { I intend to continuously switch between technologies (Netflix or Ca- } \\
\text { ble TV) when consuming social media services }\end{array}$ & \\
\hline VSI03 & $\begin{array}{l}\text { I intend to seek variety among technologies (Netflix or Cable TV) I } \\
\text { am already familiar with. }\end{array}$ & \\
\hline VS04 & $\begin{array}{l}\text { Overall, I intend to alternate between technologies (Netflix or Cable } \\
\text { TV) }\end{array}$ & \\
\hline OSL01 & In everyday life, I like having change and making novel experiences & \multirow{4}{*}{$\begin{array}{l}1=\text { Strongly Disagree } / 7 \\
=\text { Strongly agree. }\end{array}$} \\
\hline OSL02 & I am always seeking for new ideas and experiences & \\
\hline OSL03 & $\begin{array}{l}\text { I prefer to lead a life that facilitates change and variety, even if this } \\
\text { means to be exposed to certain risks }\end{array}$ & \\
\hline OSL04 & It is appealing to always do something different & \\
\hline ASL01 & Recently, I experience (too much change/too less change) & \multirow{3}{*}{$\begin{array}{l}\text { 7-point semantic differ- } \\
\text { ential scale }\end{array}$} \\
\hline ASL02 & Recently, I do (always something different/always the same) & \\
\hline ASL03 & $\begin{array}{l}\text { Recently, I make (too many new experiences/too less new experi- } \\
\text { ences) }\end{array}$ & \\
\hline VST01 & $\begin{array}{l}\text { To have a little variety, I occasionally like to change between tech- } \\
\text { nologies (Netflix or Cable TV) I know }\end{array}$ & \multirow{4}{*}{$\begin{array}{l}1=\text { Strongly Disagree } / 7 \\
=\text { Strongly agree. }\end{array}$} \\
\hline VST02 & $\begin{array}{l}\text { There are many technologies at whom I permanently switch when } \\
\text { consuming social media services }\end{array}$ & \\
\hline VST03 & $\begin{array}{l}\text { There are many technologies where I always switch among a few so- } \\
\text { cial media services }\end{array}$ & \\
\hline VST04 & $\begin{array}{l}\text { To not always consume the same technologies, I seek variety among } \\
\text { a few technologies that I am already familiar with }\end{array}$ & \\
\hline MOTI01 & $\begin{array}{l}\text { I find seeking variety between technologies (Netflix or Cable TV) to } \\
\text { be enjoyable }\end{array}$ & \multirow{3}{*}{$\begin{array}{l}1=\text { Strongly Disagree } / 7 \\
=\text { Strongly agree. }\end{array}$} \\
\hline MOTI02 & $\begin{array}{l}\text { The actual process of seeking variety between technologies (Netflix } \\
\text { or Cable TV) is pleasant }\end{array}$ & \\
\hline MOTI03 & $\begin{array}{l}\text { I have fun seeking variety between (Netflix or Cable TV) technolo- } \\
\text { gies }\end{array}$ & \\
\hline MOTE01 & $\begin{array}{l}\text { Seeking variety between technologies (Netflix or Cable TV) will im- } \\
\text { prove my way of consuming social media services }\end{array}$ & \multirow{3}{*}{$\begin{array}{l}1=\text { Strongly Disagree } / 7 \\
=\text { Strongly agree. }\end{array}$} \\
\hline MOTE02 & $\begin{array}{l}\text { The advantages of seeking variety between technologies (Netflix or } \\
\text { Cable TV) will outweigh the disadvantages }\end{array}$ & \\
\hline MOTE03 & $\begin{array}{l}\text { Overall, seeking variety between technologies (Netflix or Cable TV) } \\
\text { will be advantageous }\end{array}$ & \\
\hline PD01 & Differences among technologies (Netflix or Cable TV) are large & \multirow{3}{*}{$\begin{array}{l}1=\text { Strongly Disagree } / 7 \\
=\text { Strongly agree. }\end{array}$} \\
\hline PD02 & Differences among technologies are easy to determine & \\
\hline PD03 & The best technology is easy to determine. & \\
\hline SP01 & $\begin{array}{l}\text { In the case of social media technologies, I clearly prefer one technol- } \\
\text { ogy (Netflix or Cable TV) relative to the other }\end{array}$ & $\begin{array}{l}1=\text { Strongly Disagree } / 7 \\
=\text { Strongly agree. }\end{array}$ \\
\hline
\end{tabular}




\section{Data Collection (Future Step)}

We will use survey methodology to gather individuals' responses to the items measuring both independent and dependent variables. The sample will be chosen from current USA users of both Netflix and cable TV. Data will be collected through Amazon Mechanical Turk, which is a web-based platform where employers (called requesters) post outsourced tasks for an anonymous network of laborers (called workers) who receive compensation for their contribution (Steelman, Hammer, and Limayem, 2014). This web site has been shown to be effective in data collection and prior studies have reported that samples collected through this platform produced similar results that those based on USA students and USA consumer panels (Steelman et al. 2014). We plan to conduct first a pilot test for checking the reliability and validity of our measurement items. For the full-sample survey, we will divide the survey in three sections: (1) items measuring participants' level of use of cable TV and Netflix, (2) items measuring our independent and dependent variables, and (3) demographics. We will also include the following recommendations to detect careless responses (Huang, Curran, Keeney, Poposki, and DeShon, 2012): (1) attention checks that have only one correct response embedded in the question, and (2) a warning statement that acknowledge participants that statistical control methods will be used to detect careless responses. To determine the minimum sample size, we follow Chin (1998)'s rule-of-thumb which establishes that a sample size should be at least 10 times (1) the largest number of formative indicators or (2) the largest number of independent variables impacting a dependent variable, whichever is greater. In our research model there are not formative indicators as discussed in the previous subsection, whereas the largest number of independent variables affecting a dependent variable is five (for variety seeking intention as seen in Figure 1). We expect to collect 500 usable responses, which is more than adequate for the PLS estimation procedures (minimum sample size is 50 participants).

\section{Data Analysis (Future Step)}

For data analysis, we will use partial least squares (PLS) technique because our study is in an early stage of theory development (Komiak and Benbasat, 2006). SmartPLS will be used as analysis tool (Ringle, Wende, and Will, 2005).

As for the measurement model, reliability and convergent validity will be assessed through three tests: (1) reliability of items (items' loadings should be equal or higher than 0.7 ), (2) internal consistency (cronbach's alpha and composite reliability values should be equal or higher than 0.7 ), and (3) average variance extracted (AVE) (this value should be equal or higher than 0.5 ). On the other hand, discriminant validity will be checked by assessing that the square root of the AVEs is higher than the correlations among the constructs.

In addition, we will check the absence of multicollinearity among variables and common method bias. The former will be performed by examining that variance inflation factor (VIF) values are less than five when performing regression analysis (Hair, Ringle, and Sarstedt, 2011). As for the latter, we will check that no single factor accounts for the majority of the variance by performing the Harman's single-factor test (Hazen, Cegielski, and Hanna, 2011).

To assess the explanatory power of our structural model, we will analyze the amount of variance explained in the endogenous constructs (R2) and paths between variables. We will also compare three models using Cohen (1988)'s method (f2). Model 1 represents the full model including control variables, Model 2 represents the effect of our theoretical constructs (excluding control variables), and Model 3 represents only the effect of the control variables, which will serve as the basis to analyze the impact of the theoretical constructs. Results supporting the relevance of our independent variables should be as follow: (1) Model 1 explains a greater variance than the one explained by Model 3, and (2) the difference in explained variance between Model 1 and Model 2 is lower than the difference between Model 1 and Model 3.

Finally, we will assess the moderation role of variety seeking tendency in the relationship between motivations and intention.

\section{IMPLICATIONS (EXPECTED)}

\section{For Theory}

Our study attempts to explain user use of technologies through a new perspective, alternating between technologies. This new approach aims to bring a progress in the field of technology usage. Indeed, previous research has 
focused on technology adoption (i.e., use of a technology without prior experimentation), technology usage continuity (i.e., use of a technology with prior experimentation), and switching to a new technology (i.e., change between two technologies, one of them with prior experimentation). However, prior studies have not considered alternating between technologies, which involves two technologies that were previously used. Accordingly, our research contribution is the theoretical construction and validation of a model that could serve as the basis for studies on this relatively new behavior in the context of information technologies.

\section{For Practice}

Considering that new technologies frequently challenge existing ones (e.g., Netflix vs. Blockbuster), a theoretical model explaining alternating between technologies may help managers to outline adequate strategies to stay competitive in the market. For example, our model suggests managers that they should not only concentrate on its own technology but also in assessing alternative technologies. Indeed, our model considers both perceived differences and the strength of preference between technologies that could be potentially competitive. Another contribution is the validation of motivations as antecedents to alternating behavior.

\section{REFERENCES}

Ajzen, I. (1985). From Intentions to Actions: A Theory of Planned Behavior. In: Action-Control: From Cognition to Behavior, J. Kuhl and J. Bechmann (eds.). Heidelberg: Springer, 11-39.

Bass, F. M., Pessemier, E., \& Lehmann, D. R. (1972). An Experimental Study of Relationships Between Attitudes, Brand Preference, and Choice. Behavioral Science, 17(6), 532-541.

Bawa, K. (1990). Modeling Inertia and Variety Seeking Tendencies in Brand Choice Behavior. Marketing Science, $9(3), 263-278$.

Berlyne, D. E. (1960). Conflict, Arousal, and Curiosity. New York, NY: McGraw-Hill.

Bhattacherjee, A., \& Lin, C.-P. (2015). A Unified Model of It Continuance: Three Complementary Perspectives and Crossover Effects. European Journal of Information Systems, 24(4), 364-373.

Chin, W. W. (1998). The Partial Least Squares Approach for Structural Equation Modelling. In: Modern Methods for Business Research, G.A. Marcoulides (ed.). Mahwah, NJ: Lawrence Erlbaum Associates, 295 336.

Cohen, J. (1988). Statistical Power Analysis for the Behavioral Sciencies. Hillsdale, NJ: Lawrence Erlbaum Associates.

Davis, F. D. (1989). Perceived Usefulness, Perceived Ease of Use, and User Acceptance of Information Technology. MIS Quarterly, 13(3), 319-340.

Davis, F. D., Bagozzi, R. P., \& Warshaw, P. R. (1992). Extrinsic and Intrinsic Motivation to Use Computers in the Workplace. Journal of Applied Social Psychology, 22(14), 1111-1132.

Deci, E. L., \& Ryan, R. M. (1985). The General Causality Orientations Scale: Self-Determination in Personality. Journal of Research in Personality, 19(2), 109-134.

Givon, M. (1984). Variety Seeking Through Brand Switching. Marketing Science, 3(1), 1-22.

Ha, J., \& Jang, S. (2013). Determinants of Diners' Variety Seeking Intentions. Journal of Services Marketing, 27(2), 155-165.

Hair, J. F., Ringle, C. M., \& Sarstedt, M. (2011). PLS-SEM: Indeed a Silver Bullet. The Journal of Marketing Theory and Practice, 19(2), 139-152. 
Hazen, B. T., Cegielski, C., \& Hanna, J. B. (2011). Diffusion of Green Supply Chain Management: Examining Perceived Quality of Green Reverse Logistics. International Journal of Logistics Management, 22(3), 373-389.

Helm, R., Gierl, H., \& Stumpp, S. (1999). Erklarung Des Konsumentenverhaltens Durch Die Optimal Stimulation Level Theorie. Marketing: ZFP, 21(3), 217-235.

Helm, R., \& Landschulze, S. (2009). Optimal Stimulation Level Theory, Exploratory Consumer Behaviour and Product Adoption: An Analysis of Underlying Structures across Product Categories. Review of Managerial Science, 3(1), 41-73.

Hoyer, W. D., \& Ridgway, N. M. (1984). Variety Seeking as an Explanation for Exploratory Purchase Behavior: A Theoretical Model. Advances in Consumer Research, 11(1), 114-119.

Huang, J. L., Curran, P. G., Keeney, J., Poposki, E. M., \& DeShon, R. P. (2012). Detecting and Deterring Insufficient Effort Responding to Surveys. Journal of Business and Psychology, 27(1), 99-114.

Huang, L. -Y., \& Hsieh, Y. -J. (2012). Consumer Electronics Acceptance Based on Innovation Attributes and Switching Costs: The Case of E-Book Readers. Electronic Commerce Research and Applications, 11(3), 218-228.

Komiak, S. Y. X., \& Benbasat, I. (2006). The Effects of Personalization and Familiarity on Trust and Adoption of Recommendation Agents. MIS Quarterly, 30(4), 941-960.

McAlister, L., \& Pessemier, E. (1982). Variety Seeking Behavior: An Interdisciplinary Review. Journal of Consumer Research, 9(3), 311-322.

Orth, U., \& Bourrain, A. (2005). Optimum Stimulation Level Theory and the Differential Impact of Olfactory Stimuli on Consumer Exploratory Tendencies. Advances in Consumer Research, 32, 613-619.

Park, C. W., \& Mittal, B. (1985). A Theory of Involvement in Consumer Behavior: Problems and Issues. Research in Consumer Behavior, 1(3), 201-232.

Petri, H. L., \& Govern, J. M. (2006). Motivación: Teoría, Investigación y Aplicaciones. Madrid, Spain: Thomson.

Raju, P. S. (1980). Optimum Stimulation Level: Its Relationship to Personality, Demographics, and Exploratory Behavior. Journal of Consumer Research, 7(3), 272-282.

Ringle, C. M., Wende, S., \& Will, A. (2005). SmartPLS 2.0 (M3) Beta, Hamburg. Available in http://www. smartpls. de.

Ryan, R. M., \& Deci, E. L. (2000). Intrinsic and Extrinsic Motivations: Classic Definitions and New Directions. Contemporary Educational Psychology, 25(1), 54-67.

Steelman, Z. R., Hammer, B. I., \& Limayem, M. (2014). Data Collection in the Digital Age: Innovative Alternatives to Student Samples. MIS Quarterly, 38(2), 355-378.

Steenkamp, J.- B. E. M., \& Baumgartner, H. (1992). The Role of Optimum Stimulation Level in Exploratory Consumer Behavior. Journal of Consumer Research, 19(3), 434-448.

Steenkamp, J.- B. E. M., Baumgartner, H., \& Van der Wulp, E. (1996). The Relationships among Arousal Potential, Arousal and Stimulus Evaluation, and the Moderating Role of Need for Stimulation. International Journal of Research in Marketing, 13(4), 319-329.

Steenkamp, J.- B. E. M., \& Van Trijp, H. C. M. (1991). The Use of Lisrel in Validating Marketing Constructs. International Journal of Research in Marketing, 8(4), 283-299. 


\section{Issues in Information Systems}

Volume 18, Issue 2, pp. 113-122, 2017

Stenovec, T. (2014). Yes, Netflix and Hulu Are Starting to Kill Cable. In: The Huffington Post. http://www.huffingtonpost.com/2014/04/17/netflix-cable_n_5168725.html

Teo, T. S., Lim, V. K., \& Lai, R. Y. (1999). Intrinsic and Extrinsic Motivation in Internet Usage. Omega 27(1), 25-37.

Van Trijp, H. C. M. (1995). Variety-Seeking in Product Choice Behavior: Theory with Applications in the Food Domain. Wageingen, Netherlands: Landbouwuniversiteit te Wageningen.

Van Trijp, H. C. M., Hoyer, W. D., \& Inman, J. J. (1996). Why Switch? Product Category: Level Explanations for True Variety-Seeking Behavior. Journal of Marketing Research, 33(3), 281-292.

Wahlers, R. G., \& Etzel, M. J. (1985). Vacation Preference as a Manifestation of Optimal Stimulation and Lifestyle Experience. Journal of Leisure Research, 17(4), 283-295.

Yoo, S. J., Han, S. -h., \& Huang, W. (2012). The Roles of Intrinsic Motivators and Extrinsic Motivators in Promoting E-Learning in the Workplace: A Case from South Korea. Computers in Human Behavior, 28(3), 942-950.

Zimbardo, P. G., Johnson, R. L., \& McCann, V. (2012). Psychology: Core Concepts. Boston, MA: Pearson. 